\title{
Wind-induced baroclinic response of Lake Constance
}

\author{
Y. Wang ${ }^{1}$, K. Hutter ${ }^{1}$, E. Bäuerle ${ }^{2}$ \\ ${ }^{1}$ Institute of Mechanics, Darmstadt University of Technology, Hochschulstr. 1, D-64289 Darmstadt, Germany \\ ${ }^{2}$ Limnological Institute, University of Constance, D-78457 Constance, Germany
}

Received: 23 February 2000 / Revised: 14 June 2000 / Accepted: 5 July 2000

\begin{abstract}
We present results of various circulation scenarios for the wind-induced three-dimensional currents in Lake Constance, obtained with the aid of a semi-spectral semi-implicit finite difference code developed in Haidvogel et al. and Wang and Hutter. Internal Kelvin and Poincaré-type oscillations are demonstrated in the numerical results, whose periods depend upon the stratification and the geometry of the basin and agree well with measured data. By solving the eigenvalue problem of the linearized shallow water equations in the two-layered stratified Lake Constance, the interpretation of the oscillations as Kelvin and Poincaré-type waves is corroborated.
\end{abstract}

Key words: Oceanography: general (limnology; numerical modeling) - Oceanography: physical (internal and inertial waves)

\section{Introduction}

The stratification in lakes is almost exclusively established by the heat input due to solar radiation. During the summer season, in temperate climate zones, a stratification given at one particular instant generally persists for a time span that is long in comparison to the time scales of the dynamic circulation which is established by the wind shear traction applied at the water surface. Only during short-lived episodes, when the shearing in the surface layer is very large (i.e., typically during strong storms), Kelvin-Helmholtz instabilities can form which then generate internal bores that destroy the stratification or may erode the thermocline. During the periods in between the change in mass distribution due to circulation dynamics is relatively small. Thus, a

Correspondence to: Y. Wang

e-mail: wang@mechanik.tu-darmstadt.de;

hutter@mechanik.tu-darmstadt.de stable underlying stratification with no movement may be assumed as an initial condition from which the temperature and velocity field may develop without forming internal instabilities.

The underlying thermo-mechanical processes can be described mathematically by the shallow water equations in the Boussinesq approximation: in these equations the vertical momentum balance reduces to the force balance between pressure gradient and gravity (buoyancy) force, and density variations are only accounted for in the buoyancy term. The equations describe both, barotropic and baroclinic processes. The former are those that develop when density variations do not exist and, in temperate zones, arise in late autumn and during winter. They also exist in a truly stratified lake or ocean basin, but are then overshadowed by the baroclinic processes that are typical for the summer seasons when the underlying stratification is strong.

There are many numerical models based on the shallow water equations in the Boussinesq approximation (Ramming and Kowalik, 1980; Simons, 1980; Oman, 1982; Pohlmann, 1987; Tee, 1987; Lehmann, 1995). Haidvogel and Beckmann (1998) also summarized many such three-dimensional models. All claim to describe these kind of wind-induced motions, and have been applied to large-scale oceanographic situations. Some three-dimensional models have been used to describe circulation flows in lakes and have had limited success (e.g. Bennett, 1977; Hollan and Simons, 1978; Oman, 1982). However these three-dimensional models or codes are limited in their applicability, or unsatisfactory, because internal wave processes are overly damped owing to the large explicit or implicit numerical diffusion that had to be built into the codes to stabilize them under common conditions.

Here, the nonlinear shallow water equations in the Boussinesq approximation, that describe wind induced circulation dynamics in enclosed basins, are integrated using a numerical semi-spectral primitive equation model (SPEM) that was modified by us with a semiimplicit time-integration in the vertical direction. For greater detail the reader is referred to Wang and Hutter 
(1998). Here our aim is the presentation of solutions to a given initial stratification and a wind stress from different directions.

In Sect. 2 we briefly outline the model. In Sect. 3 various scenarios of wind-driven baroclinic processes in Lake Constance are studied and the predicted Kelvin and Poincaré-type oscillations can be displayed in the results. In Sect. 4, by solving the eigenvalue problem of the linearized shallow water equations of the twolayered Lake Constance, the interpretation of the oscillations as Kelvin and Poincaré-type waves can be ascertained. We conclude with a summary and some remarks in Sect. 5.

\section{Numerical model}

We briefly describe here the numerical model as constructed by Haidvogel et al. (1991) and changed by Wang and Hutter (1998) to allow large-time-temporal integration.

The basic hydrodynamic equations consist of the balance equations of mass, momentum and energy as well as a thermal equation of state. We apply these hydrodynamic equations in the shallow water and Boussinesq approximations, with the Coriolis term and the hydrostatic pressure equation implemented. A further simplification is achieved by imposing a rigid lid at the water surface. Under these assumptions the field equations read

$$
\begin{aligned}
& \frac{\partial u}{\partial x}+\frac{\partial v}{\partial y}+\frac{\partial w}{\partial z}=0, \\
& \frac{\partial u}{\partial t}+\mathbf{v} \cdot \operatorname{grad} u-f v \\
& \quad=-\frac{\partial \phi}{\partial x}+\frac{\partial}{\partial x}\left(v_{H} \frac{\partial u}{\partial x}\right)+\frac{\partial}{\partial y}\left(v_{H} \frac{\partial u}{\partial y}\right)+\frac{\partial}{\partial z}\left(v_{V} \frac{\partial u}{\partial z}\right), \\
& \frac{\partial v}{\partial t}+\mathbf{v} \cdot \operatorname{grad} v+f u \\
& \quad=-\frac{\partial \phi}{\partial y}+\frac{\partial}{\partial x}\left(v_{H} \frac{\partial v}{\partial x}\right)+\frac{\partial}{\partial y}\left(v_{H} \frac{\partial v}{\partial y}\right)+\frac{\partial}{\partial z}\left(v_{V} \frac{\partial v}{\partial z}\right), \\
& 0=-\frac{\partial \phi}{\partial z}-\frac{\rho g}{\rho_{0}}, \\
& \frac{\partial T}{\partial t}+\mathbf{v} \cdot \operatorname{grad} T \\
& \quad=\frac{\partial}{\partial x}\left(D_{H}^{T} \frac{\partial T}{\partial x}\right)+\frac{\partial}{\partial y}\left(D_{H}^{T} \frac{\partial T}{\partial y}\right)+\frac{\partial}{\partial z}\left(D_{V}^{T} \frac{\partial T}{\partial z}\right), \\
& \frac{\rho-\rho_{0}}{\rho_{0}}=-\alpha \times\left(T-T_{0}\right)^{2}, \quad\left(T \text { in }{ }^{\circ} \mathrm{C}\right) .
\end{aligned}
$$

Here a Cartesian coordinate system $(x, y, z)$ has been used; $(x, y)$ are horizontal, and $z$ is vertically upwards, against the direction of gravity; $\mathbf{v}=(u, v, w), f, \rho, \rho_{0}, \phi, g, T, \alpha$ are, respectively, the velocity vector, Coriolis parameter, density, reference density $\left(\rho_{0}=1000 \mathrm{~kg} \mathrm{~m}^{-3}\right.$ at temperature $\left.T_{0}=4{ }^{\circ} \mathrm{C}\right)$, dynamic reduced pressure $\left(\phi=p / \rho_{0}, p\right.$ is pressure), gravity force $\left(g=9.8 \mathrm{~m} \mathrm{~s}^{-2}\right)$, temperature, thermal expansion coefficient. For Lake Constance (fresh water) $\alpha$ is taken as $\alpha=6.8 \times 10^{-6}\left({ }^{\circ} \mathrm{C}\right)^{-2}$. Furthermore,
$v_{H}, v_{V}$ are horizontal and vertical momentum, $D_{H}^{T}, D_{V}^{T}$, horizontal and vertical heat diffusivities.

To solve the system of differential equations numerically, a semi-spectral model was designed with semiimplicit integration in time. The model is based on the semi-spectral model SPEM developed by Haidvogel et al. (1991), in which the vertical dependence of the model variables is represented as an expansion in a finite modified Chebyshev polynomial set, and in the horizontal finite difference representations are used. SPEM employs in its original version an explicit scheme for temporal integration and thus is numerically only conditionally stable, i.e., the allowable time step is restricted by spatial resolutions. Therefore this model was extended by Wang and Hutter (1998) to account for implicit temporal integration: because of the small water depths of lakes in comparison to the ocean, the original SPEM model had to be altered to permit economically justifiable time steps in the computation of the circulation of a lake. In Wang and Hutter (1998) several finite difference schemes, implicit in time, were introduced; that scheme which uses implicit integration in time for the viscous terms in the vertical direction was the most successful one.

By using a $\sigma$-transformation, a lake domain with varying topography is transformed to a new domain with constant depth, and this region is once again transformed in the horizontal co-ordinates by using conformal mapping which maps the shore as far as possible onto a rectangle. Uniformity in grid size distribution is intended, because numerical oscillations (instabilities) preferably occur on the small scale; however, it is difficult to achieve it in complex geometries. In such cases, to attain as far as possible an uniform grid distribution, a bounding line, which deviates in some segments from the actual lake boundary, is used for the conformal mapping. In these segments the actual boundaries can only be approximated by a step function, and in the numerical computations the land areas within the grid system must be excluded by a special masking technique (Wilkin et al., 1995).

This numerical code has proved its suitability in several lake applications, including diffusion problems (Hutter and Wang, 1998), substructuring procedures (Chubarenko et al., 1999; Wang and Hutter, 2000) and wave dynamics in wind-driven circulation (Hutter et al., 1998). For this reason we refrain from prescribing the numerical code and directly pass on to the application of this code to baroclinic motions in Lake Constance.

\section{Baroclinic response in Lake Constance}

\subsection{Parameter selection}

Lake Constance (Bodensee, Fig. 1a), the second largest Alpine lake in Europe, consists of three basins, the main basin of Upper Lake Constance and Lake Überlingen which together form Upper Lake Constance (Obersee), and the Lower Lake Constance (Untersee); the latter is dynamically decoupled from the others by the $5 \mathrm{~km}$ long 
Upper Lake Constance
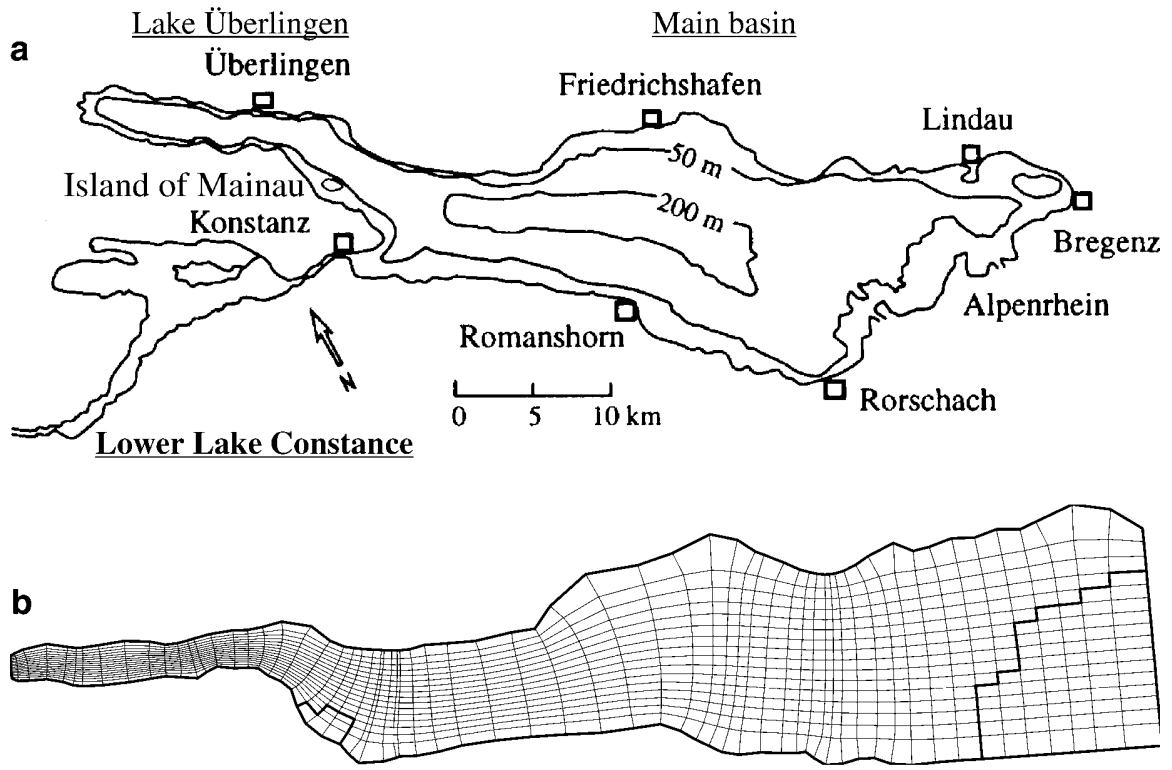

Fig. 1. a Lake Constance principal bathymetry with indication of several towns and three sub-basins: Upper and Lower Lake Constance and Lake Überlingen, b computational grid for "global" current simulation in the Upper Lake Constance and Lake Überlingen
River Rhine. Henceforth we will only be concerned with Upper Lake Constance and will for brevity also refer to it as Lake Constance. It is approximately $64 \mathrm{~km}$ long and $16 \mathrm{~km}$ wide. The Island of Mainau is situated in Lake Überlingen (with maximum, mean, depth of $153 \mathrm{~m}, 100 \mathrm{~m}$ ), close to its mouth at the southeastern slope. It forms the southern end of the subsurface glacial sill with a maximum depth of $101 \mathrm{~m}$. This sill and the Island of Mainau together form a natural hydrodynamic barrier, separating Lake Überlingen from the main basin of Upper Lake Constance which has a maximum depth of $253 \mathrm{~m}$.

In our computations we work with a grid net having $65 \times 17$ nodal points in the horizontal direction with an average grid size of approximately $1 \mathrm{~km}$, whereas in the vertical 30 Chebyshev polynomials will be employed. The area of the Island of Mainau (here modelled as a peninsula because the water depth between the island and the shore is only $1 \sim 2 \mathrm{~m}$ ) was masked as a land area; the same was done for the segment RorschachBregenz, indicated in Fig. 1b as the shoreline with thick lines.

This numerical model is driven by prescribing at each nodal point on the free surface of the discretized domain time series of the wind stress vector. In principle, therefore, arbitrary spatial distributions of the wind forcing can be prescribed if so desired; however, we will here restrict attention to relatively simple scenarios: uniformly distributed wind in a preferred direction and Heaviside-type in time, e.g. wind uniform in space and constant in time, only lasting the first two days. A wind speed of $V_{\text {wind }}=4 \mathrm{~m} \mathrm{~s}^{-1}, 10 \mathrm{~m}$ above the water surface, is used, corresponding to a wind stress of $0.035 \mathrm{~N} \mathrm{~m}^{-2}$ at the water surface. Similarly, lateral stresses obey a viscous sliding law. As for other boundary conditions, the rigid lid assumption is applied at the free surface, and at the bottom of the lake the flow is tangential to the bed. Furthermore, it will be assumed that no heat flows across the free or basal surfaces: $\mathrm{d} T / \mathrm{d} \mathbf{n}=0$, where $\mathbf{n}$ is the unit normal vector of the boundary surface. Such an assumption is acceptable for the short duration of simulations, e.g. processes lasting for days, but not for months.

The stratification varies through the seasons as the solar radiation heats the upper most layers of the lake, and turbulence diffuses this heat to greater depths. By late summer these processes will have established a distinct stratification, that essentially divides the water mass into a warm upper layer (called epilimnion), a cold deep layer (hypolimnion) which are separated by a transition zone (metalimnion), in which the epilimnion temperatures above it are transferred to the hypolimnion temperatures below it. Vertical temperature gradients in this layer are larger than in the epi- and hypolimnion with a maximum at the thermocline. A vertical temperature profile, typical of a late summer situation for Alpine lakes, is (see e.g. Bäuerle et al., 1998; Hutter, 1984b),

$$
\begin{aligned}
T(t & =0) \\
& =\left\{\begin{array}{ll}
17-2 \exp (-(z+10) / 5), & \mathrm{z} \geq-10 \mathrm{~m}, \\
5+10 \exp ((z+10) / 20), & \mathrm{z}<-10 \mathrm{~m}
\end{array} \quad\left[{ }^{\circ} \mathrm{C}\right] ;\right.
\end{aligned}
$$

with a well-mixed upper $10 \mathrm{~m}$ layer, a rapid temperature drop at about $10-40 \mathrm{~m}$ depth and a nearly constant temperature of $5{ }^{\circ} \mathrm{C}$ below $40 \mathrm{~m}$. Equation (2) will be chosen as the initial temperature profile from which also the initial density distribution can be computed according to the thermal equation of state, Eq. (1)6. For computational and physical purposes this representation is sufficiently accurate.

The governing three-dimensional non-stationary shallow water Eqs. (1) account for the anisotropy of the diffusivity both in the momentum and heat conduction equations, i.e., the horizontal diffusivities differ from the 
vertical diffusivities, and those of momentum are not the same as those of heat. Convection (or advection) is treated equally in all space directions. Chosen values for momentum and energy equations are as follows:

$$
\begin{aligned}
& v_{V}= \begin{cases}0.04, \quad z>-20 \mathrm{~m}, \\
0.004, \quad-20 \mathrm{~m} \geq z \geq-40 \mathrm{~m},\left[\mathrm{~m}^{2} \mathrm{~s}^{-1}\right], \\
0.02, \quad z<-40 \mathrm{~m}\end{cases} \\
& v_{H}=1.0 \mathrm{~m}^{2} \mathrm{~s}^{-1}, \\
& D_{V}^{T}= \begin{cases}0.0005, & z>-20 \mathrm{~m}, \\
0.00005, & -20 \mathrm{~m} \geq z \geq-40 \mathrm{~m},\left[\mathrm{~m}^{2} \mathrm{~s}^{-1}\right], \\
0.0001, & z<-40 \mathrm{~m},\end{cases} \\
& D_{H}^{T}=1.0 \mathrm{~m}^{2} \mathrm{~s}^{-1},
\end{aligned}
$$

(a) near western end

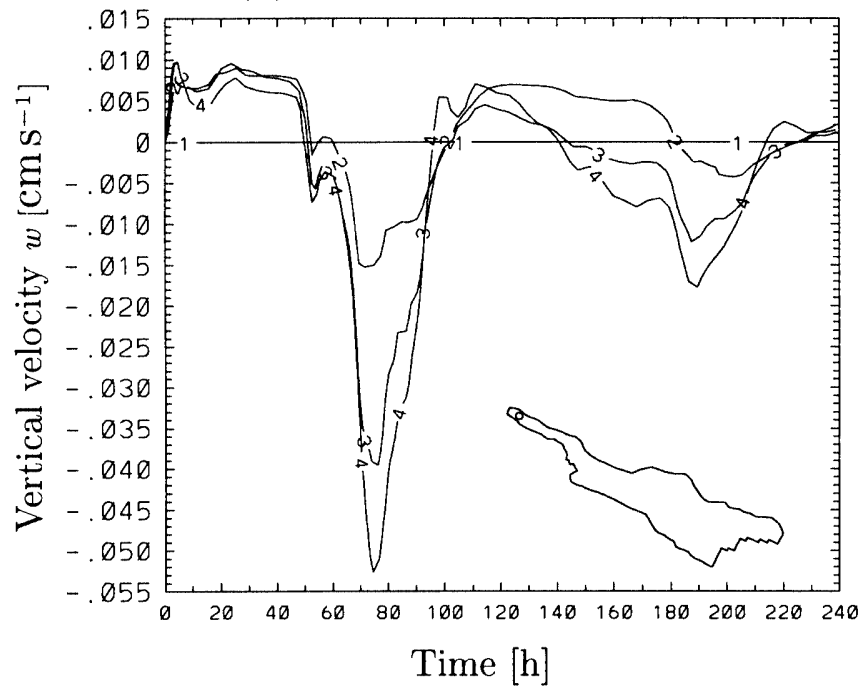

(c) near southern shore

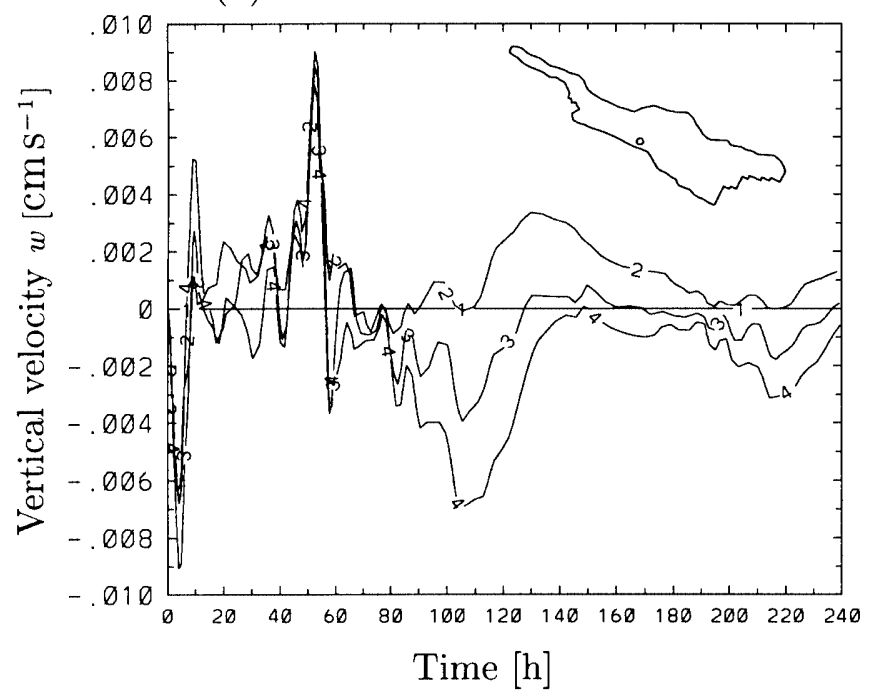

Fig. 2a-d. Time series of the vertical velocity component $w$ at the four near-shore points around the basin, indicated insets a western, b northern, c southern and $\mathbf{d}$ eastern shore, at different depths subject in which the horizontal diffusivities are simply chosen as constants. For the non-constant vertical diffusivities, this choice accounts for the requirement of numerical stability and the fact that the momentum and thermal diffusivities are considerably smaller in the metalimnion region than in the epilimnion above and the hypolimnion below. This is so because the thermocline prevents diffusion through this "interface". The diffusivities in the hypolimnion are also smaller than in the epilimnion because of its smaller ambient turbulence. Compared with realistic measured values they are basically in the range that is thought to be physically acceptable, even though they are still somewhat large (see e.g. Hutter, 1984a; Maiss et al., 1994a, b; Peeters, 1994). Strictly speaking, these coefficients should be temporally changed, depending on the alterations of the water temperature distribution and the velocity field. Such depen-

(b) near northern shore

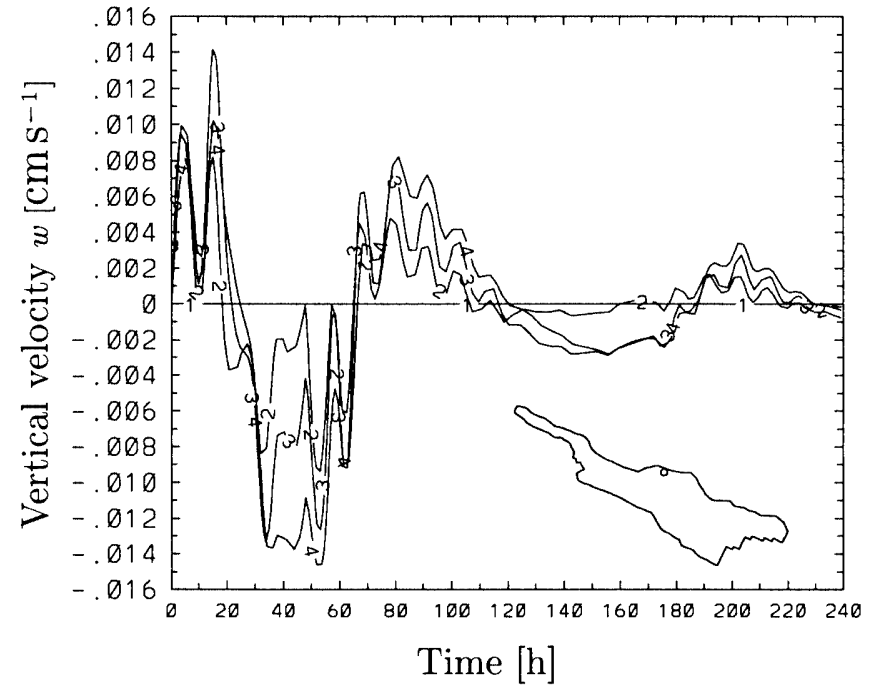

(d) near eastern end

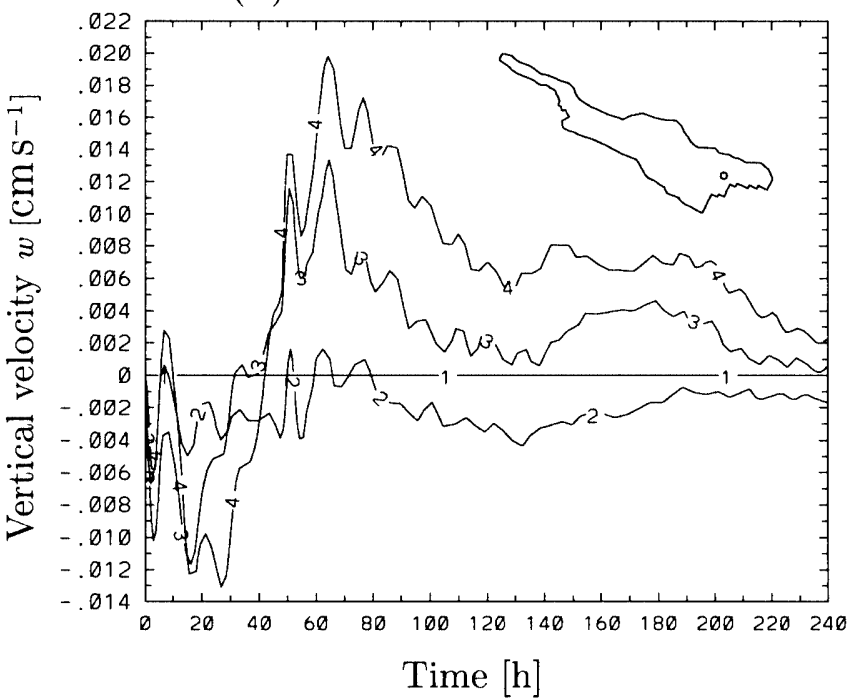

to constant wind from $305^{\circ} \mathrm{NW}$ (in the longitudinal direction of the basin) lasting two days. The labels $(1,2,3,4)$ correspond to the depths $(0,20,40,60) \mathrm{m}$, respectively 
dences can be modelled by turbulent closure conditions. Here, as a zero-order closure approximation, we do not consider the temporal changes of the diffusivities.

\subsection{Uniform wind in the longitudinal direction $\left(305^{\circ} \mathrm{NW}\right)$}

In this subsection we consider the response of Lake Constance to an impulsively applied constant wind force in the longitudinal direction (along the main axis of the lake) from the west with a duration of two days. The model is started at rest and integrated over a period of ten days.

Figure 2 shows a time series of the vertical velocity component $w$ at various depths of four nearshore positions shown in the insets. Somewhat simplified, the motion commences with an upwelling of approximately

(a) near western end

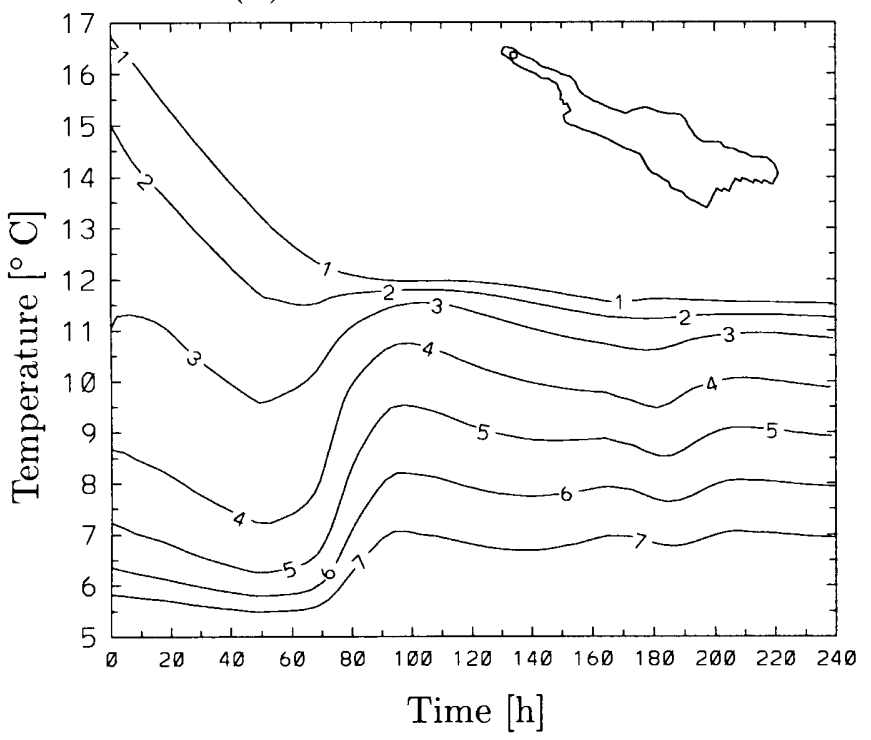

(c) near southern shore

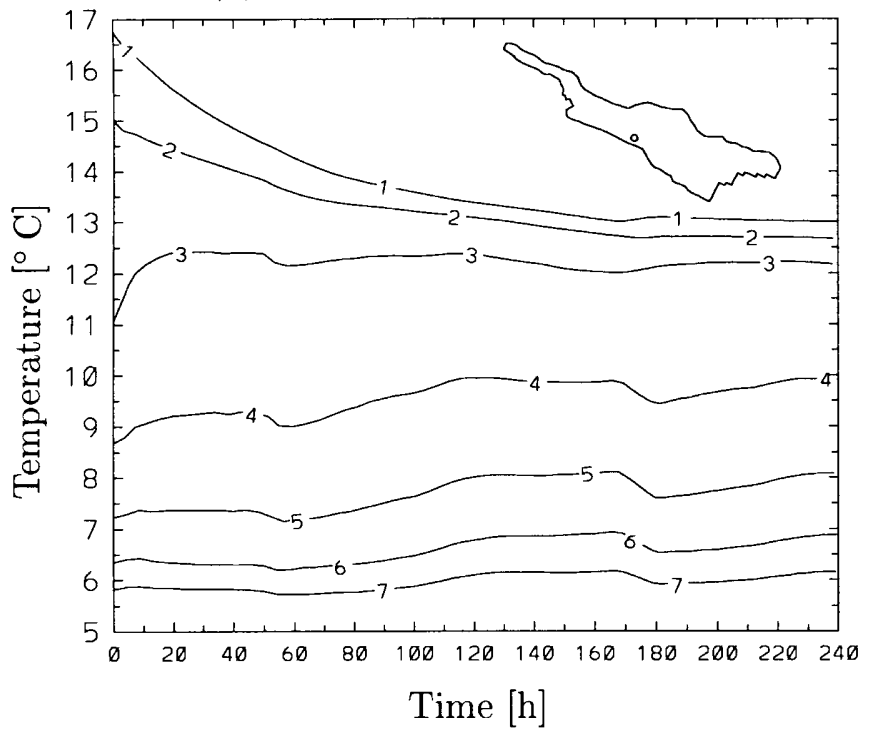

$48 \mathrm{~h}$ duration at the western end of Lake Überlingen that goes over into a downwelling after wind cessation; at $t \simeq 75 \mathrm{~h}$ the maximum rebounding of the vertical velocities is formed, that relaxes after $20 \mathrm{~h}$ into an upwelling again. Correspondingly, the motion starts at the eastern end with a downwelling which after $40 \mathrm{~h}$ becomes an upwelling, at least at the lower depths. In the northern (southern) mid boundary points there occurs first an upwelling (downwelling) and thereafter a downwelling (upwelling), followed by another still weaker sequence of downwelling and upwelling events. This behaviour is, clearly, due to the Coriolis force that causes a velocity drift to the right and therefore is responsible for the initial downwelling (upwelling) at the southern (northern) shore. The motion is characterized by oscillation, of which two conspicuous components can be clearly identified. The longer periodic oscillation, barely visible

(b) near northern shore

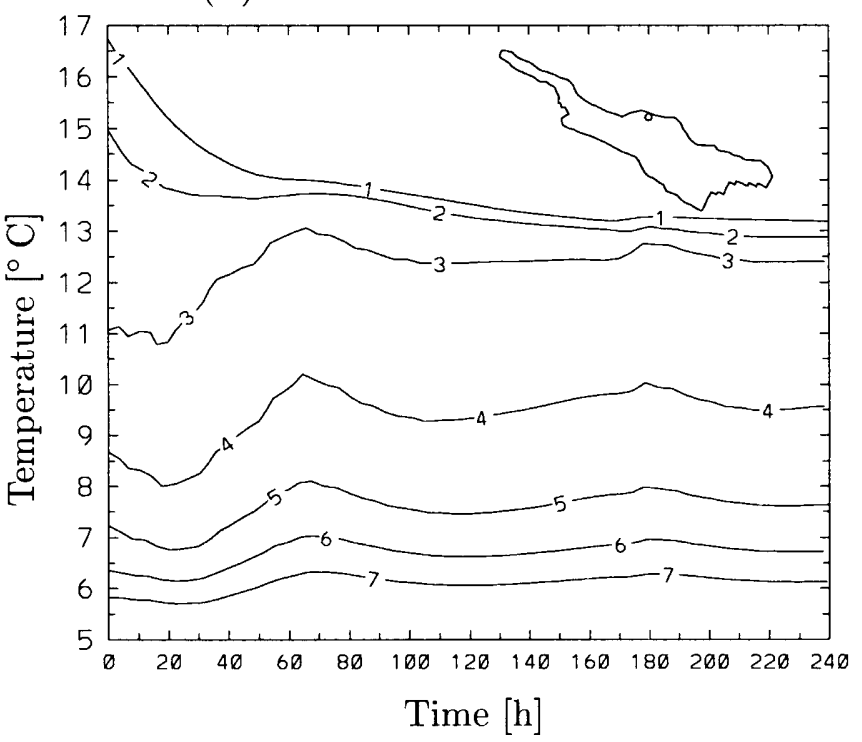

(d) near eastern end

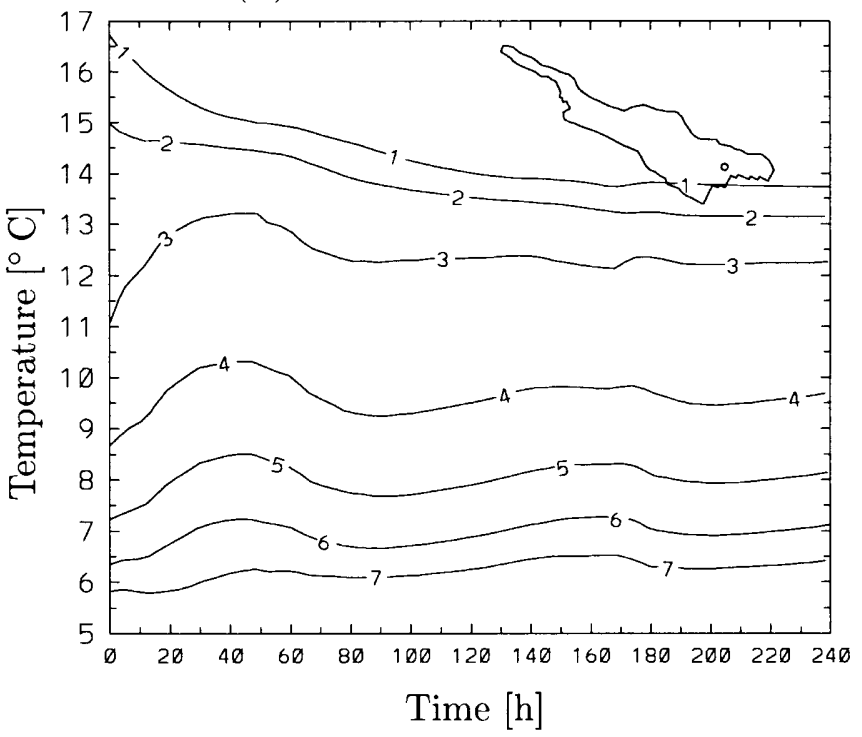

Fig. 3a-d. Time series of the temperature at the four near-shore points, the same as in Fig. 2 (indicated in the insets) at various depths subject to a two-day constant wind from $305^{\circ}$. The labels $(1,2, \ldots, 7)$ correspond to the depths $(0,10, \ldots, 60) \mathrm{m}$, respectively 
in the overall behaviour but conspicuously indicated by the strong downstroke signals, can be identified as an internal Kelvin-type wave, the shorter periodic one as a Poincaré-type wave. We will in the next section provide convincing details for this interpretation. In Fig. 2a for the western end point the downstroke after the wind cessation is conspicuously seen at $\sim 75 \mathrm{~h}$. If we follow this downwelling signal around the lake, then Fig. 2a, c, d, b shows for $\sim 75,105,130,155 \mathrm{~h}$, respectively, that the four points are encountered counter-clockwise around the basin, with a travel time of approximately 100-105 h around the basin. This period is in good agreement with previous observations of Kelvin waves (Zenger et al., 1989). Figure 2 also discloses very clearly the short periodic oscillations that are superimposed on the longterm trend in the signals. These oscillating signals may be interpreted as standing Poincaré-type waves.

\section{(a) near western end}

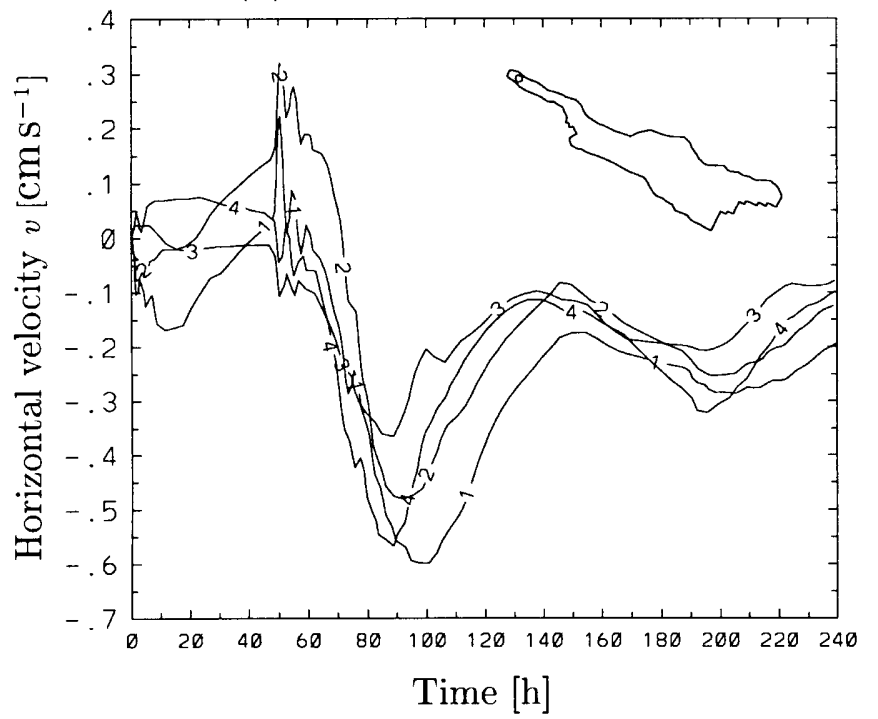

(c) near southern shore

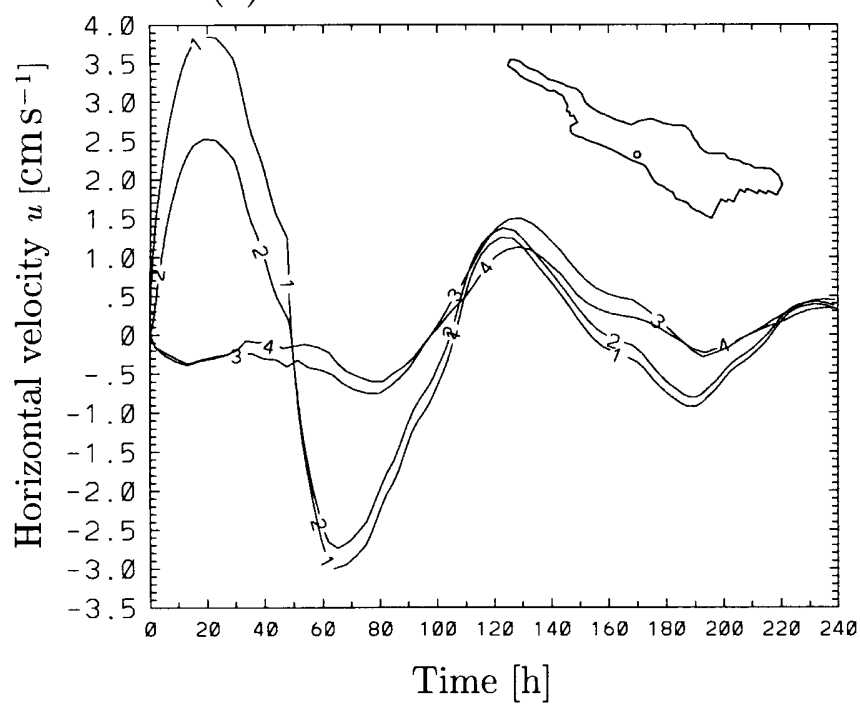

The Kelvin-type oscillations can be seen likewise in the temperature time series at the same four near-shore points around the lake displayed in Fig. 3. This figure clearly shows that the metalimnion experiences a strong increase (decrease) of temperature whenever downwelling (upwelling) strokes arise. In the epilimnion (above $\sim 15 \mathrm{~m}$ depth) and in the hypolimnion (below $\sim 45 \mathrm{~m}$ depth) the temperature change is relatively small, with the exception of a rapid temperature drop at the surface at the beginning which is due to turbulent mixing. Contrary to this Kelvintype behaviour, the Poincaré-type oscillation cannot be identified in the temperature-time series of Fig. 3.

Figure 4 shows the longshore horizontal velocity at the same four positions of the western (a), northern (b), southern (c) and eastern shores (d) as functions of time at various vertical locations. The Kelvin-type wave may be more clearly identified. (b) near northern shore

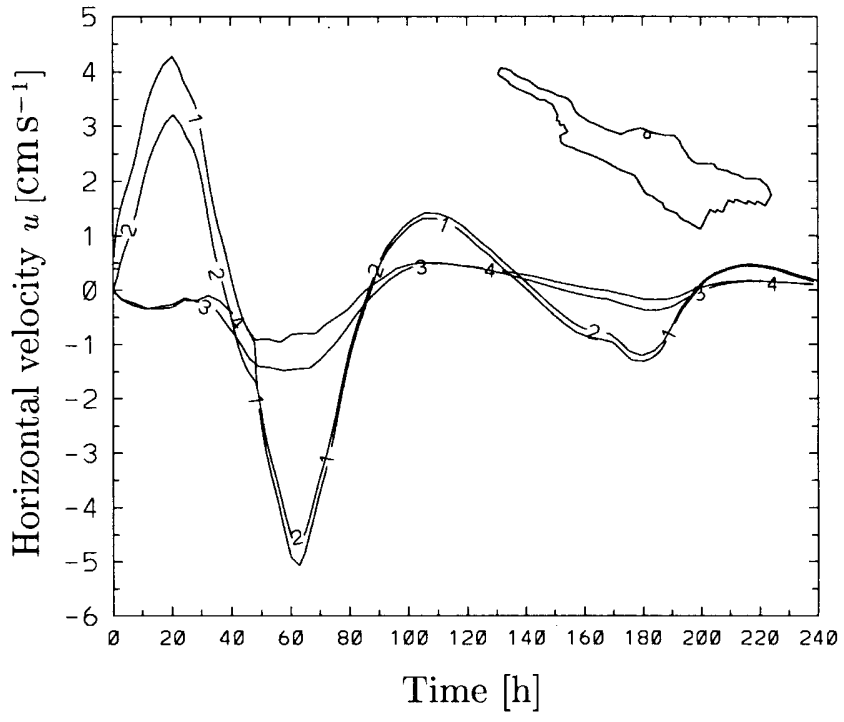

(d) near eastern end

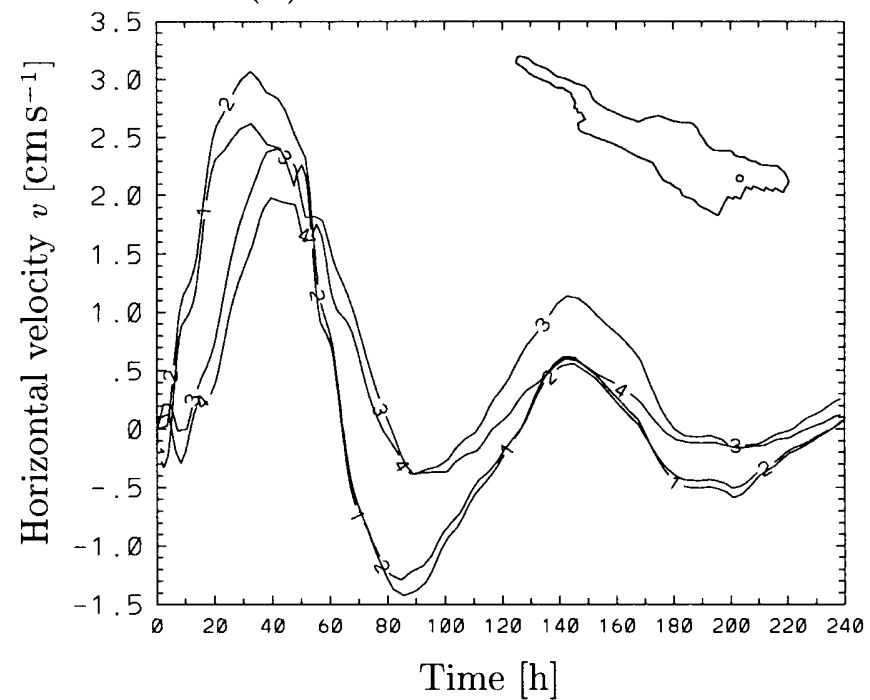

Fig. 4a-d. Time series of the shore-parallel horizontal velocity component at the same four near-shore positions and the same wind input as in Figs. 2 and 3 . The labels $(1,2,3,4)$ correspond to the depths $(0,20,40,60) \mathrm{m}$, respectively 

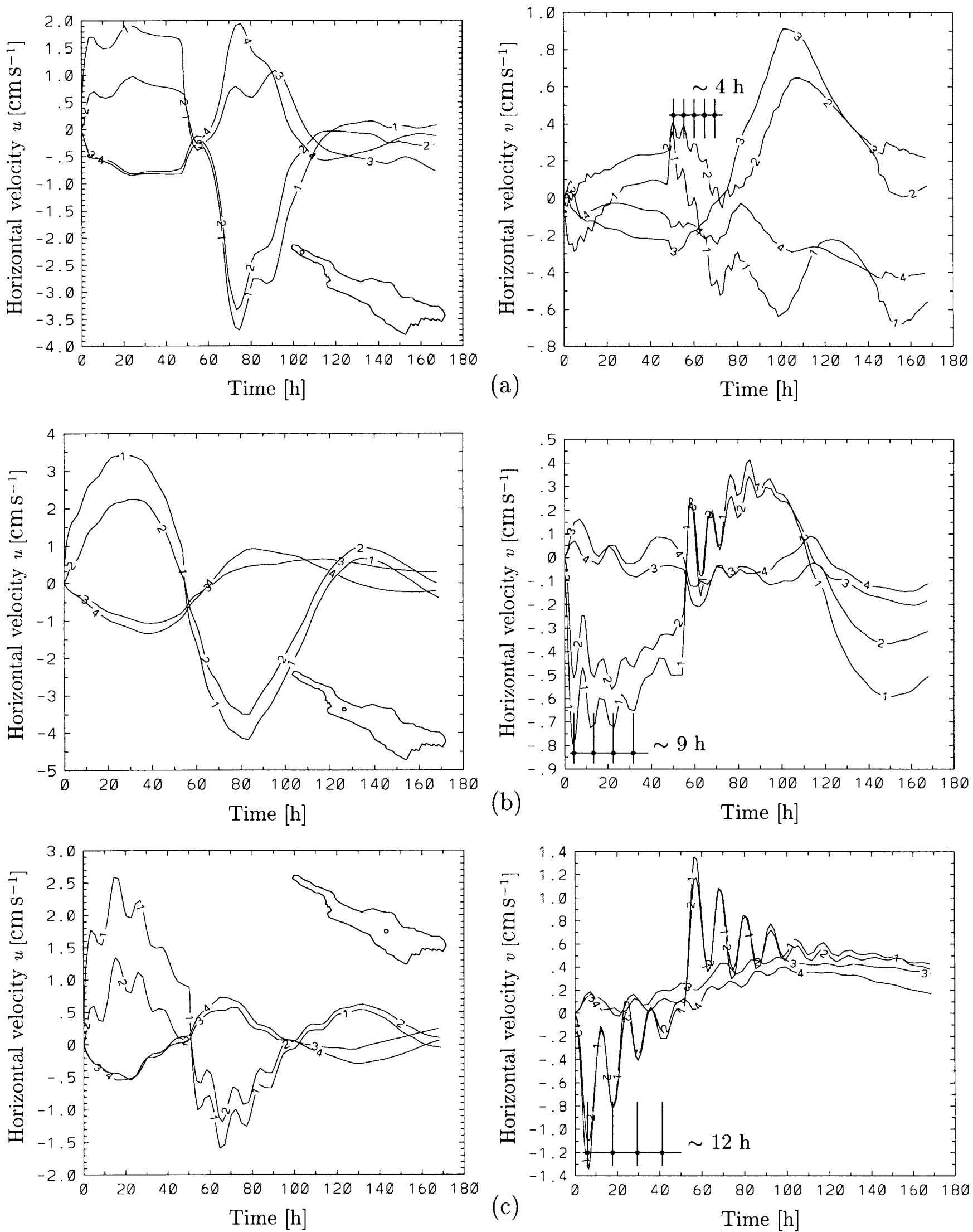

Fig. 5a-c. Temporal evolution of the horizontal velocity components $u$ (left) and $v$ (right) for three locations (indicated in the insets) from left to right along the longitudinal direction in the stratified Lake

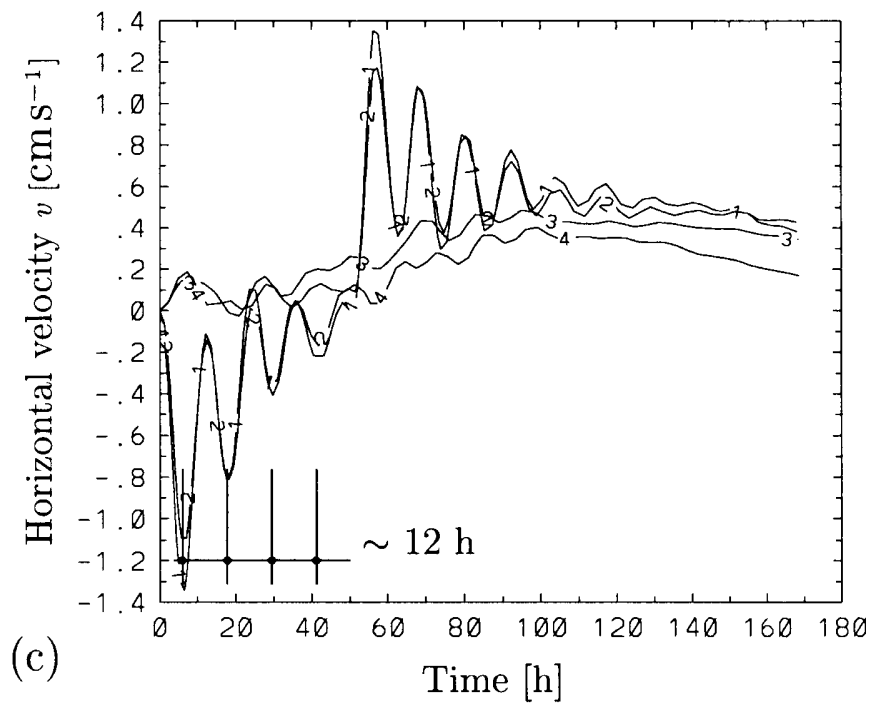

Constance subject to a constant wind from $305^{\circ} \mathrm{NW}$ lasting two days. The labels $(1,2,3,4)$ correspond to the depths $(0,20,40,60) \mathrm{m}$, respectively 

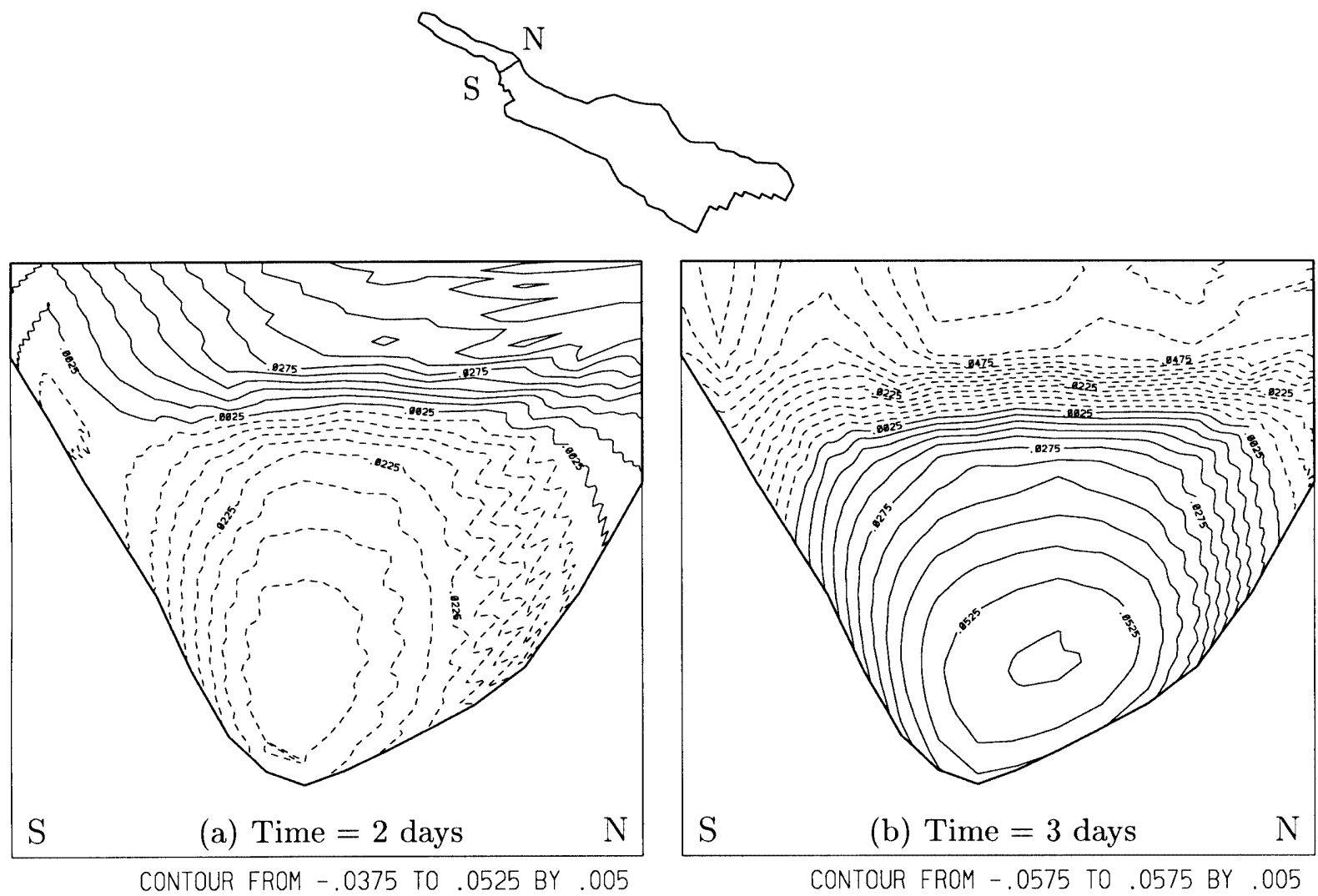

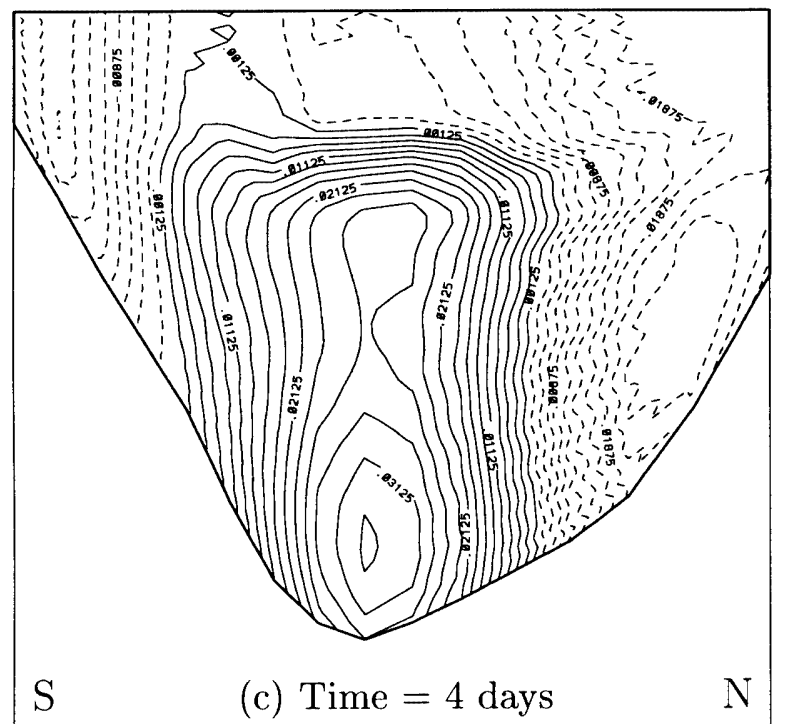

CONTOUR FROM - .02375 TO .03375 BY .0025

Fig. 6. Isolines of the horizontal velocity component $u$ in the cross section between Lake Überlingen and the main basin of Upper Lake Constance indicated in the top inset subject to a two-day constant wind from $305^{\circ} \mathrm{NW}$ approximately in the longitudinal direction (out

In Fig. 5 the time series of the horizontal velocity components $u$ (left) and $v$ (right) in three different locations from left to right along the longitudinal direction in the stratified Lake Constance at different depths are displayed. The longer periodic Kelvin-type oscillations can be observed in all three locations, at least from plots of the longitudinal component of the

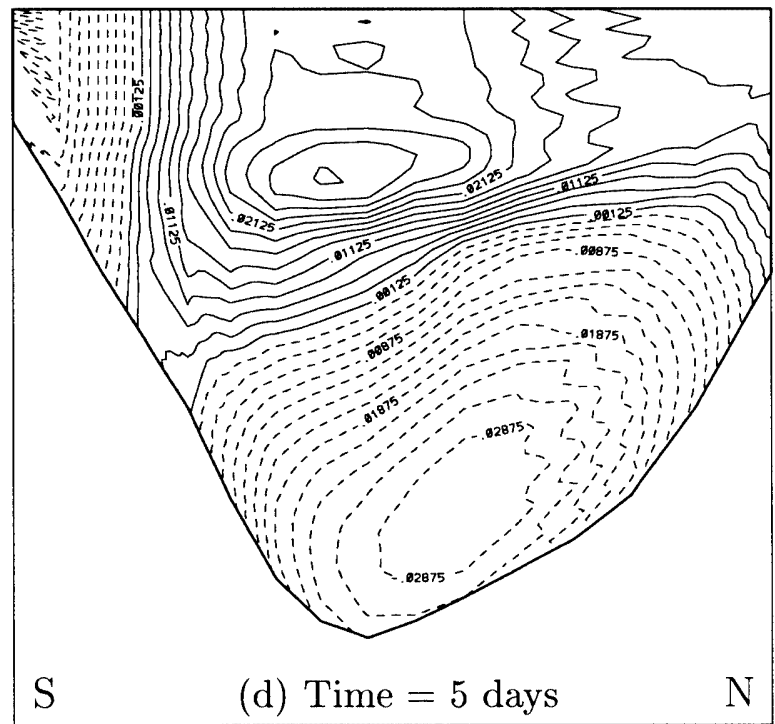

CONTOUR FROM -.02875 TO .03125 BY .0025

of the page) for four different time points after the wind ceases. The solid (dashed) curves correspond to the positive (negative), indicating the flow out of (into) the page

horizontal velocity (left panels in Fig. 5). Furthermore, the Poincaré-type oscillations can likewise be seen, mainly from the transverse component of the velocity (right panels in Fig. 5), whose periods depend upon the extension of the basin in the transverse direction. From left to right along the longitudinal direction of Lake Constance (from above to below in Fig. 5), with the 
addition of the lake width, the periods of the Poincaretype oscillations are added. At a position, $4 \mathrm{~km}$ to the east of the western end of Lake Überlingen (Fig. 5a), where the width of the lake is only $2.5 \mathrm{~km}$, a Poincarétype wave with the period of approximately $4 \mathrm{~h}$ can be recognized from the cross component of the velocity $v$ shortly after the start and end of the wind, even though this wave then dies away quickly. The period of $4 \mathrm{~h}$ agrees with observations at the western end of Lake Überlingen (Hollan, 1974). At the location between Lake Überlingen and the Upper Lake Constance, a period of $9 \mathrm{~h}$ can be seen. This period was also observed at the same location (Heinz, 1995). At the centre of the Upper Lake Constance, where the lake width reaches its maximum, the period of the Poincare-type oscillation is nearly $12 \mathrm{~h}$, which was also demonstrated by observations (Hollan, 1974; Heinz, 1995). It shows that, for a lake with complex geometry, the Poincaré-type oscillations display complex local features, which correspond to different modes of internal oscillations.

If we observe the flow through a cross section, the complexity and the local structure of the flow can be easily detected. In Fig. 6 the isolines of the velocity component normal to the cross section are displayed in this cross section for four different time moments after the wind ceases. Two days after the wind set-up (just before the cessation of the wind, Fig. 6a), the current in the upper layer is along the wind direction toward SE, while in the layer below it is against the wind towards NW. When the wind ceases, the flow oscillates back. One day after the wind ceases (Fig. 6b), all currents are in the opposite direction of the flow before the wind ceases: in the upper layer toward NW and in the below layer toward SE. One further day later (Fig. 6c), only the current at the lower depths of the cross section centre is toward SE, while near the shores and in the upper layer the current is toward NW. For three days after the cessation of the wind, the motion oscillates back again, its direction is approximately the same as before the cessation of the wind, except near the southern shore.

The dependence of the total kinetic energy on the wind direction is worked out in terms of a polar diagram, which displays the variation of the total kinetic energy stored in the stationary circulation of the rectangular basin as a function of the direction of the wind. We compute the water motion subject to a constant wind from different directions (in intervals of $20^{\circ}$ ). The polar diagrams of the total kinetic energy are displayed in Fig. 7 for one day (Fig. 7a) and two days (Fig. 7b) after the wind start-up, respectively. The stored, total energy depends very strongly on the wind direction. The geographical direction of maximum exposure coincides approximately with the longitudinal direction of the lake. The kinetic energy under a transverse wind is only $7 \%$ of that for a longitudinal wind at the end of the first day and a sixth at the end of the second day. It is also interesting that the maximum total kinetic energy two days after the wind began amounts only to a half of that for one day after the wind began.

\subsection{Uniform wind in the transverse direction}

It is known that for wind-forcing in the transverse direction Poincaré-type waves are more easily excited. We also performed computations for a uniform transverse wind (from $215^{\circ} \mathrm{SW}$ ) lasting two days. Figure 8 shows the horizontal velocity components $u$ (left) and $v$ (right) at the same three positions as in Fig. 5. From these time series Poincaré-type oscillations generated by a transverse wind can be more clearly identified than those in Fig. 5 obtained subject to the longitudinal wind.

One typical feature of Poincaré waves is that the horizontal projection of the velocity vector rotates clockwise (in the Northern Hemisphere). This behaviour can be inferred from the left and right panels in Fig. 8 (only for the second and the third positions), where the diamond symbols mark times at which $v$ reaches a minimum and $u$ lies between a relative maximum and minimum. This is reminiscent of a nearly $45^{\circ}$ phase shift of the $y$-component behind the $x$-component, exactly what is expected by Poincare-type waves.

It is also interesting to notice that a periodic oscillation with the period of approximately $20 \mathrm{~h}$ can be clearly recognized from the longitudinal component of the velocity $u$ in Lake Überlingen (left panel in

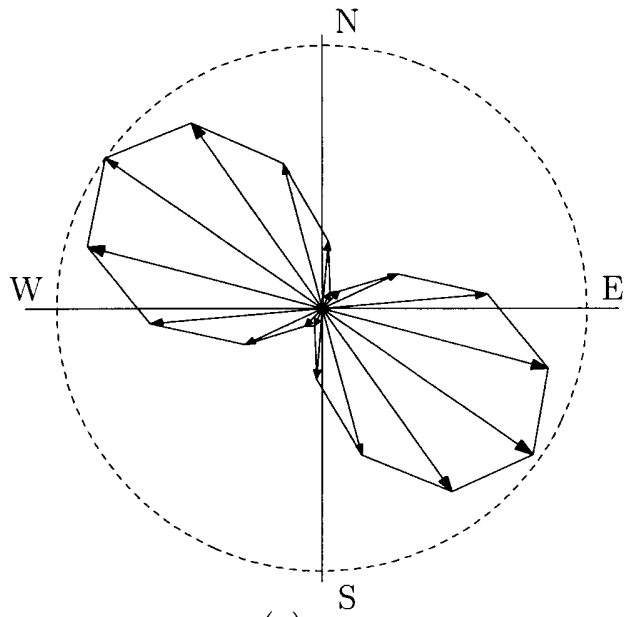

(a)

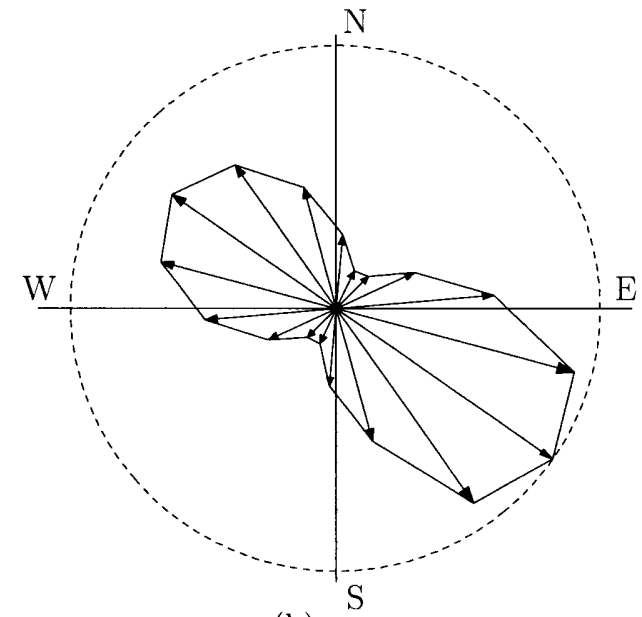

(b)
Fig. 7a, b. Total kinetic energy computed a for one day and b two days after the wind set-up subject to constant wind from different directions. The directions of the arrows are the wind directions (for an interval of $20^{\circ}$ ) around the basin, their lengths indicate the magnitudes of the total kinetic energy. The dashed circles show the maximum value of the total kinetic energy in all directions, which is a $1.10 \times 10^{10} \mathrm{~N} \mathrm{~m}$, but $5.75 \times 10^{9} \mathrm{~N} \mathrm{~m}$ for $\mathbf{b}$ 

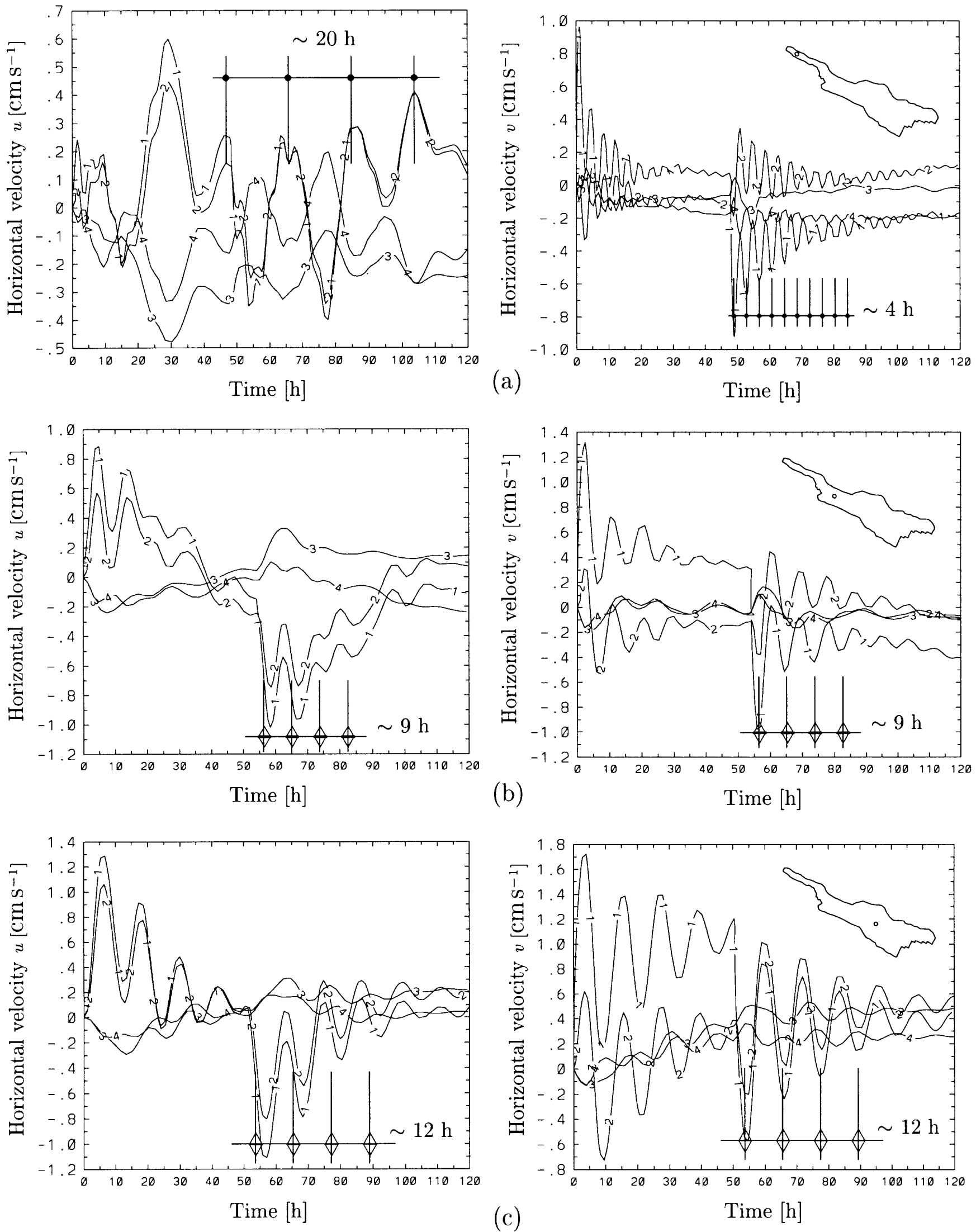

Fig. 8a-c. Temporal evolution of the horizontal velocity components $u$ (left) and $v$ (right) for three positions from left to right in the stratified Lake Constance (as indicated in the insets) subject to a

constant wind from $215^{\circ} \mathrm{SW}$ (in the transverse direction) lasting two days. The labels $(1,2,3,4)$ correspond to the depths $(0,20,40,60) \mathrm{m}$ 
Fig. 8a). Most probably, it is the local longitudinal Kelvin-type oscillation, which might be trapped in Lake Überlingen due to the sill and Island of Mainau at its mouth, which dynamically partly separates Lake Überlingen from the main basin of Upper Lake Constance.

\section{Internal seiches: an eigenvalue problem of the two-layer model}

To corroborate the interpretation of the oscillations emerging from the wind-induced motion, an eigenvalue problem is now solved. The ensuing analysis of free oscillations will be based upon a two-layer fluid system on the rotating Earth. We employ the shallow water equations of a two-layer fluid, ignore frictional effects and thus may presume the layer velocity vectors to be independent of the depth coordinate. The depth integrated linearized momentum and conservation of mass equations then take the form

$\frac{\partial \mathbf{V}_{1}}{\partial t}+f \mathbf{k} \times \mathbf{V}_{1}+g h_{1} \operatorname{grad} \zeta_{1}=0$,

$\frac{\partial \zeta_{1}}{\partial t}+\operatorname{div} \mathbf{V}_{1}+\operatorname{div} \mathbf{V}_{2}=0$

$\frac{\partial \mathbf{V}_{2}}{\partial t}+f \mathbf{k} \times \mathbf{V}_{2}+g(1-\varepsilon) h_{1} \operatorname{grad} \zeta_{1}+g \varepsilon h_{2} \operatorname{grad} \zeta_{2}=0$,

$\frac{\partial \zeta_{2}}{\partial t}+\operatorname{div} \mathbf{V}_{2}=0$

with the boundary conditions for a closed water basin

$\mathbf{V}_{1} \cdot \mathbf{n}=0 \quad$ and $\quad \mathbf{V}_{2} \cdot \mathbf{n}=0$.

Here, $f$ is the Coriolis parameter, $\mathbf{k}$ a unit vector in the $z$-direction and $g$ the gravity constant. $\mathbf{V}_{i}(i=1,2)$ are the horizontal components of the volume transport vector in the $i$-th layer; $\zeta_{i}$ is the displacement of the free surface and interface, $h_{i}$ the layer depth and $\epsilon=\left(\rho_{2}-\rho_{1}\right) / \rho_{2}$, where $\rho_{i}$ are the constant densities of the two layers, respectively. $\mathbf{n}$ is the unit normal vector along the boundary.

It is well known that for constant depth basins, $h=h_{1}+h_{2}=$ const, the two-layer Eqs. (4), (5) can be decoupled into two one-layer models governing the free barotropic and baroclinic oscillations separately. But for Lake Constance this is not the case because variations of bottom topography are quite strong, therefore the twolayer Eqs. (4), (5) must be solved simultaneously.

Using the harmonic dependence on time of the form

$$
\begin{aligned}
& \left(\mathbf{V}_{1}(x, y, t), \zeta_{1}(x, y, t), \mathbf{V}_{2}(x, y, t), \zeta_{2}(x, y, t)\right) \\
& \quad=\left(\mathbf{V}_{1}^{*}(x, y), \zeta_{1}^{*}(x, y), \mathbf{V}_{2}^{*}(x, y), \zeta_{2}^{*}(x, y)\right) \mathrm{e}^{i \omega t},
\end{aligned}
$$

with frequency $\omega$ and the amplitudes $V_{1,2}^{*}$ and $\zeta_{1,2}^{*}$ in Eq. (4) an eigenvalue problem emerges for the eigenvalue $\omega$ and the mode functions $V_{1,2}^{*}$ and $\zeta_{1,2}^{*}$ which can be routinely determined (Bäuerle, 1981).

The temperature stratification Eq. (2) can be approximately expressed by a two-layer model with $\epsilon=8.8 \times$
$10^{-4}, h_{1}=13 \mathrm{~m}$ and $h_{2}=h_{2}(x, y)$. Using these values in the Eq. (4) with the boundary conditions (5) allows evaluation of the horizontal structure of the corresponding oscillations. In Table 1, we have listed eigenfrequencies and eigenperiods of the fundamental (first) mode and several superinertial modes obtained this way.

It would be exhausting to present the horizontal structures of all free internal oscillations which have been recorded and identified in Lake Constance. We restrict ourselves to two of them: the first (fundamental, subinertial) mode, which is to be considered as the dominant one, and the twelfth (superinertial) mode, which preferentially is excited in the middle of the Upper Lake Constance by winds in the transverse direction.

The motion of the 1 . mode of oscillations is the rotation-modified fundamental longitudinal oscillation of the basin (Kelvin-type wave). The structure of the fundamental mode is presented in the form of $1 / 8$-cycle snapshots of the interface displacement covering one half-cycle (Fig. 9). As the influence of the Earth's rotation is of importance for the internal motions in lakes of this size, the standing mode is transformed into an amphidromic system by the rotation. The contours are given at intervals of $10 \%$ of the maximum elevation of the mode. It is clearly seen that the mode is an amphidromic system in which the wave propagates counter-clockwise around the (positive) amphidromic point (indicated by the closed circle). If we were to display the current vectors for different moments as well, we would see that the velocity field of this fundamental mode is shore-bound and counter-clockwise around the basin as expected for Kelvin-type waves. This first mode of eigenoscillations obtained by the eigenvalue problem of the two-layer model is in good agreement with the Kelvin-type wave in the three-dimensional numerical results of wind-induced circulations (Figs. 2-4), not only its period but also its shore-bound feature.

To give an example of the highly complex horizontal structure of the superinertial, Poincare-type internal oscillations, we choose the twelfth mode $(T=11.9 \mathrm{~h})$ of the two layer model which exhibits one welldeveloped, clockwise rotating amphidromic system situated at the broadest part of the basin (in the middle of the Upper Lake Constance). The horizontal structure of this mode, which is identified by means of the flow ellipses, and the corresponding horizontal velocity distributions for four successive phases $\omega t=0$, $\pi / 4, \pi / 2,3 \pi / 4$ of the upper, those of the lower layer possess the rather similar structure, but in opposite direction. In Fig. 10a each ellipse represents a trajec-

Table 1. Eigen frequencies and periods of the fundamental oscillation (1. mode) and three superinertial oscillations (11., 12. and 13. modes) subject to the stratification (2), which is replaced by a two-layer model with $\varepsilon=8.8 \times 10^{-4}, h_{1}=13 \mathrm{~m}$ and $h_{2}=h_{2}(x, y)$

\begin{tabular}{lllllll}
\hline Mode & 1. & $\ldots$ & 11. & 12. & 13. & $\ldots$ \\
\hline Frequency $\left[\times 10^{-4} \mathrm{~s}^{-1}\right]$ & 0.1691 & $\ldots$ & 1.417 & 1.471 & 1.542 & $\ldots$ \\
Period $[\mathrm{h}]$ & 103.2 & $\ldots$ & 12.3 & 11.9 & 11.3 & $\ldots$ \\
\hline
\end{tabular}




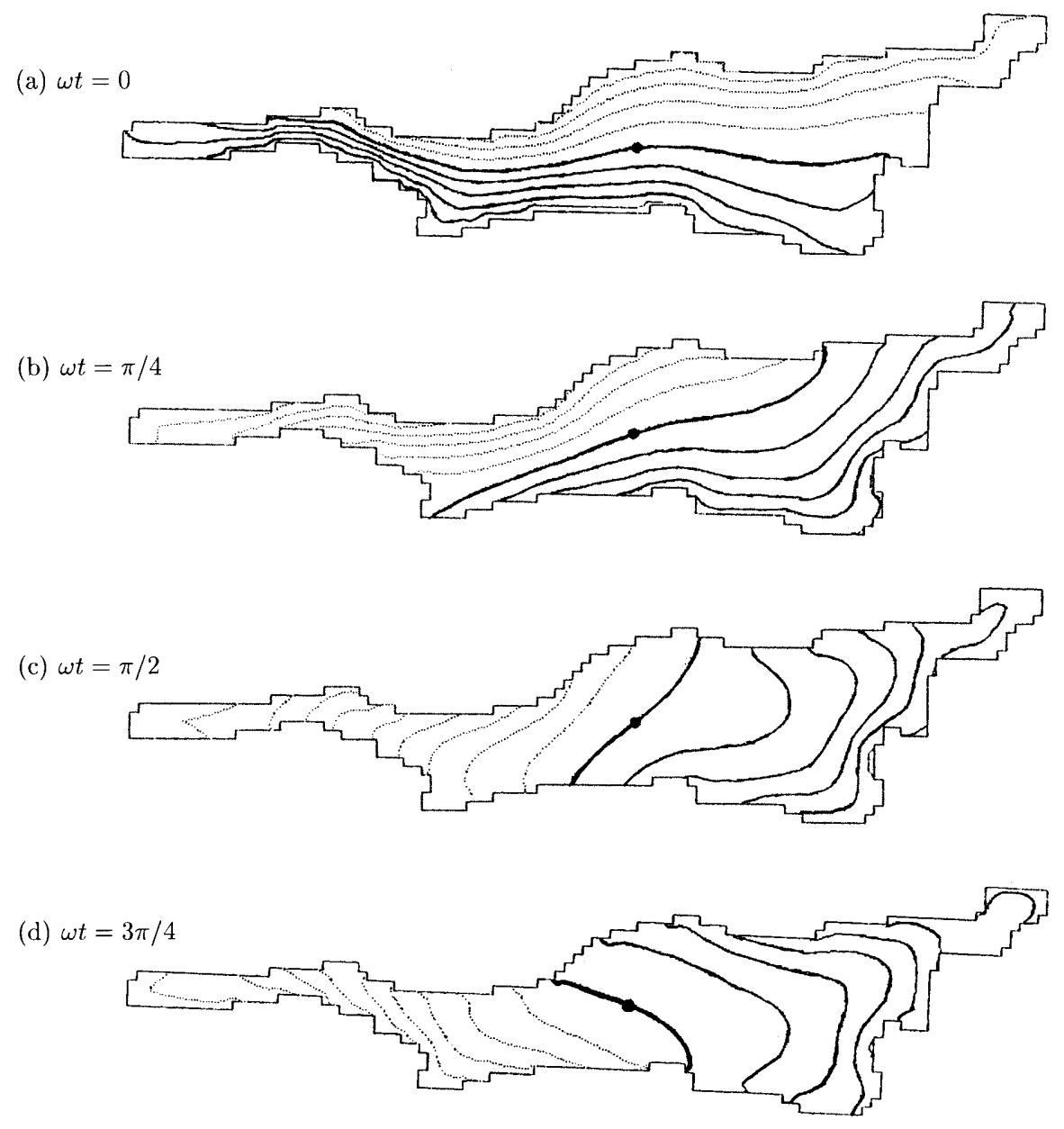

Fig. 9a-d. Interface displacement of the first mode (Kelvin-type oscillation) at $1 / 8$ cycle time intervals covering one half-cycle. The thicker line represents the instantaneous line of zero vertical displacement; negative contour lines are broken. The closed circle indicates the (positive) amphidromic point. The second half of the cycle continues with reversed displacements tory of a particle, which moves periodically around the centre of the respective ellipse. The size of the ellipses gives an indication of the excursion a particle encounters. The clockwise veering of the current vectors in the central part of the basin is clearly seen from Fig. 10bd. It is just the feature of the oscillation with the period of $12 \mathrm{~h}$ viewed in the time series of the wind-induced motion computed by the three-dimensional model (Fig. 8c).

From observations (Hollan, 1974; Heinz, 1995) we know that periods of approximately $12 \mathrm{~h}$ with clockwise veering currents are dominating the spectra at the centre of the Upper Lake Constance. This agrees with the twelfth mode of eigen oscillations of the two-layer numerical model. In general, Poincaré-type internal oscillations have smaller periods (always superinertial) the narrower the part of the basin where they occur. Here we only want to touch on observed short-period, free internal oscillations in the transverse direction of Lake Überlingen with periods of about $4 \mathrm{~h}$, which Hollan (1974) explained as the response of stratified Lake Überlingen to local winds in the transverse direction. Calculations with a numerical two-layer model of high resolution (Bäuerle, 1994) show that, in accordance with observations, the $4 \mathrm{~h}$ mode is restricted to the very end of Lake Überlingen. Further observational evidence for this fact is given by Heinz (1995) in extracting a 9-h period from the spectra of a measuring site between Lake Überlingen and the main basin of Upper Lake Constance. Such a wave should be found in a higher mode, it seems that the computation with higher resolution (near this domain) may be necessary.

Many other modes (e.g. 11.and 13. modes) of eigen oscillations possess complex structure and are hardly excited by uniform winds. Therefore, it seems that the fundamental subinertial Kelvin-type oscillation (1. mode) and the superinertial Poincaré-type oscillations (e.g. 12. mode) can be easily excited by a spatially uniform wind. The other modes may occur under more complex wind distributions. Which of the superinertial Poincaré-type oscillations actually possesses relatively simple structure should depend on the value of the internal Rossby radius compared to the width of the basin. In the calculated three-dimensional wind-induced circulation in Sect. 3 these kinds of waves could indeed be easily identified from the velocity field. Their behaviour is the same as in the eigen oscillations: Kelvin-type oscillations circulate counter-clockwise around the basin and possess large amplitudes near the shore; Poincare-type oscillations occur mainly in the centre of the basin and rotate in the clockwise direction. The periods of the oscillations estimated from the windinduced circulations and the eigen oscillations basically coincide. 
(a) Elliptical fluid particle trajectories

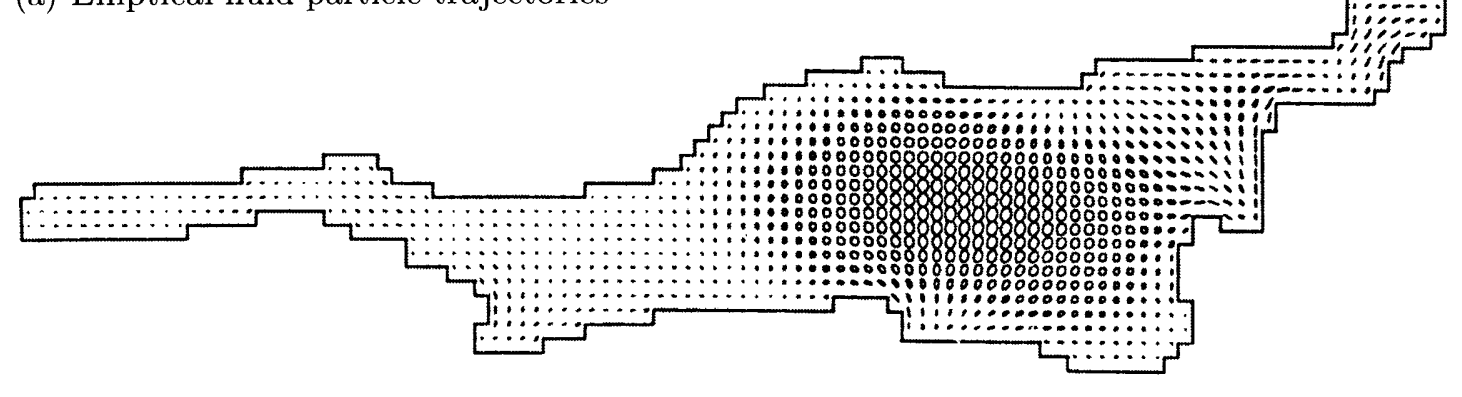

(b) Horizontal velocity for four successive phasees
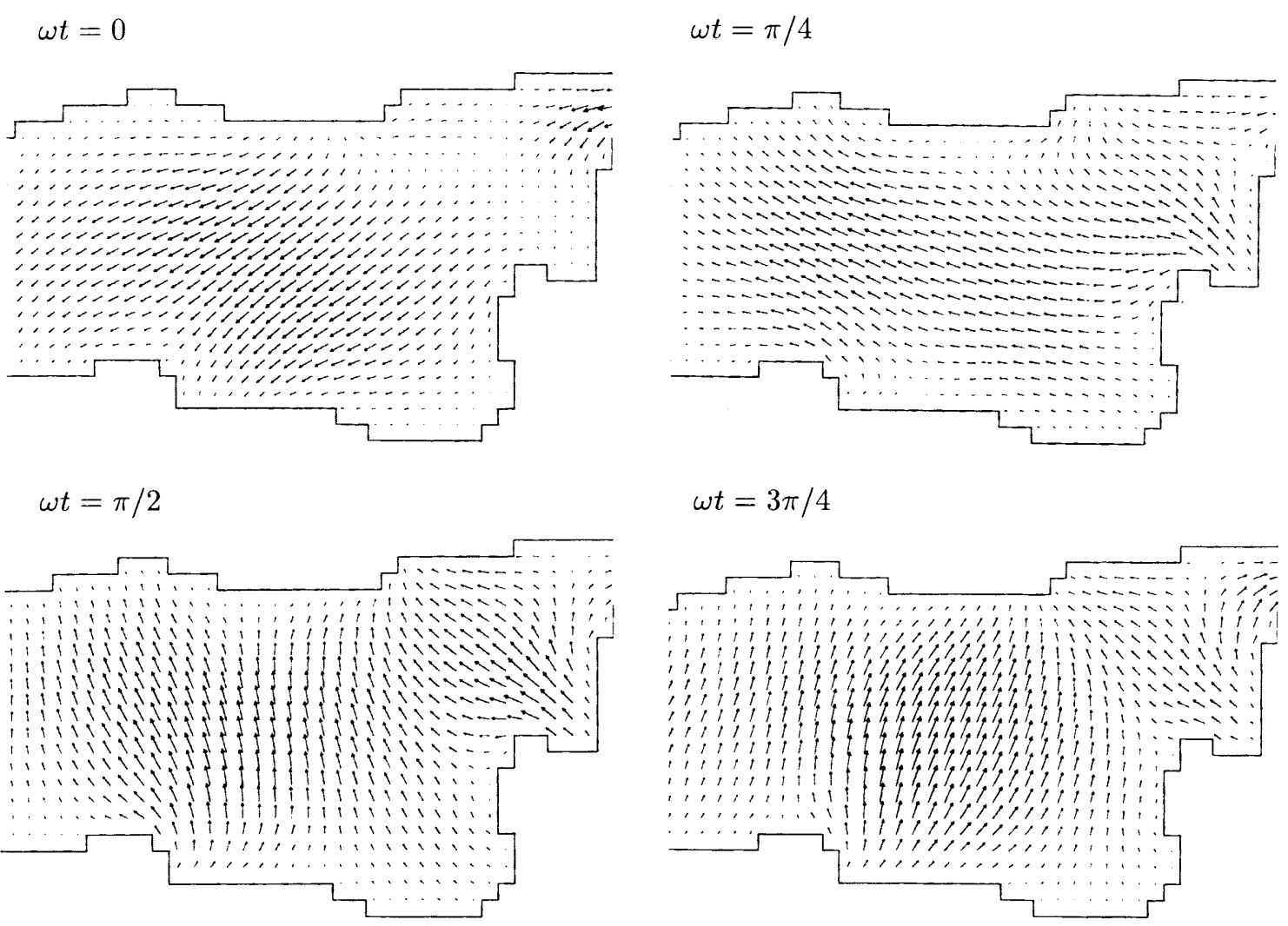

Fig. 10. a Elliptical fluid particle trajectories and $\mathbf{b}$ the corresponding horizontal velocities for four successive phases at $1 / 8$ cycle time intervals for the twelfth internal oscillation mode (Poincare-type

\section{Concluding remarks}

The internal response of medium-size lakes (as they exist in Alpine regions and other mountainous areas) to wind forcings is dominated by Kelvin and Poincaré-type wave dynamics. We have reported on the three-dimensional wind-induced baroclinic response of Lake Constance. Direct response to (simple) wind forcing and the oscillating behaviour after wind ceased were studied. It was demonstrated that this behaviour was well predicted. In particular, the dominant Kelvin- and Poincarétype waves were reasonably reproduced, despite the fact that the attenuation is still somewhat larger than in real lakes of comparable size. The periods and features of the fundamental subinertial Kelvin-type wave, which is oscillation), plotted only for the region where this mode occurs. The second half of the cycle continues with reversed currents

shore-bound, and the three superinertial Poincaré-type waves, which occur mainly in the centre of the basin and whose periods increase $(4 \mathrm{~h}, 9 \mathrm{~h}$ and $12 \mathrm{~h})$ from left to right along the longitudinal direction with increasing basin width, were clearly identified from the calculated three-dimensional wind-induced flow field. These periods are well in accordance with the observations and the solutions of the eigenvalue problem.

The performance of the model can still be amended, i.e., diffusive mechanisms reduced, by using a larger number of Chebyshev polynomials; computations, however, may become unduly long. The choice of the horizontal and (more so) vertical diffusivities is very crucial; in fact the velocity field depends on the selection of the diffusivities. However, while our program allows 
to choose the values in the range that is thought to be physically acceptable, the vertical distribution and temporal variation can still not be chosen with sufficient assurance of physical reliability. This dictates that the Reynolds-closure conditions must be computed along with the balances of mass, momentum and energy.

A step towards an improvement of this situation would be to add to these balance laws a closure condition of higher order, say by using an algebraic formula or one-parameter-closure scheme with a differential equation for the Reynolds stresses or a two-parameter-closure scheme with two differential equations, such as the $k-\varepsilon$ model. The former can be easily performed (see e.g. Svensson, 1978; Heaps, 1987; Rodi, 1993; Song and Haidvogel, 1994), however the latter still faces problems of instability under strong wind forcing, especially for three-dimensional modelling in lakes (see e.g. Güting, 1998; Güting and Hutter, 1998).

Acknowledgements. Topical Editor N. Pinardi thanks S. Pierini and J. O. Back-haus for their help in evaluating this paper.

\section{References}

Bäuerle, E., Die Eigenschwingungen abgeschlossener, zweigeschichteter Wasserbecken mit variabler Topographie, Rep. Inst. Meereskunde, Kiel, 85, 1981.

Bäuerle, E., Transverse baroclinic oscillations in Lake Überlingen, Aq. Sci., 56(2), 145-160, 1994.

Bäuerle, E., D. Ollinger, and J. Ilmberger, Some meteorological, hydrological, and hydrodynamical aspects of Upper Lake Constance, in Eds. E. Bäuerle and U. Gaedke, Lake Constance: characterisation of an ecosystem in transition, Arch. Hydrobiol. Spec. Issues Advanc. Limnol. 53, E. Schweizerbart'sche Verlagsbuchhandlung, Stuttgart, 31-83, 1998.

Bennett, J. R., A three-dimensional model of Lake Ontario's summer circulation, Part I: comparision with observations, J. Phys. Oceanogr., 7, 591, 1977.

Chubarenko, B. V., Y. Wang, I. P. Chubarenko, and K. Hutter, Simulation of wind-driven currents around a near-shore island by substructuring techniques. Island Mainau (Lake Constance) as an example. Ecol. Modell., in press, 1999.

Güting, P., Dreidimensionale Berechnung windgetriebener Strömung mit einem k-ع-Modell in idealisierten Becken und dem Bodensee, Shaker Aachen, ISBN 3-8265-3795-5, 343, 1998.

Güting, P., and K. Hutter, Modeling wind-induced circulation in the homogeneous Lake Constance using $k$-epsilon closure, Aq. Sci., 60, 266-277, 1998.

Haidvogel D. B., and A. Beckmann, Numerical models of the coastal ocean, The Sea, 10, 1997.

Haidvogel, D. B., J. L. Wilkin, and R. Young, A semi-spectral primitive equation ocean circulation model using vertical sigma and orthogonal curvilinear horizontal coordinates, J. Comput. Phys., 94, 151-185, 1991.

Heaps, N. S., Three-dimensional coastal ocean models, Coast. Estuar. Sci., 4, 208, 1987.
Heinz, G., Strömungen im Bodensee. Ergebnisse einer Meßkampagne im Herbst 1993, Mitteil. VAW ETH Zürich, 135, 237, 1995.

Hollan, E., Strömungsmessungen im Bodensee, Sechster Ber. $A W B R, \mathbf{6}, 112-187,1974$.

Hollan, E., and T. J. Simons, Wind-induced changes of temperature and currents in Lake Constance, Arch. Meteorol Geophys. Bioklim., Ser. A27, 333-373, 1978.

Hutter, K., Fundamental equations and approximations, in Hydrodynamics of lakes, CISM-lectures, Ed. K. Hutter, Springer, Berlin Heidelberg, New York, 1984a.

Hutter, K., Mathematische Vorhersage von barotropen und baroklinen Prozessen im Zürich- und Luganersee, Vierjahresschr. Naturforsch. Ges. Zürich, 129, 51-92, 1984 b.

Hutter, K., G. Bauer, Y. Wang, and P. Güting, Forced motion response in enclosed lakes, Coastal and estuarine studies, 54, 137-166, 1998.

Lehmann, A., A three-dimensional baroclinic eddy resolving model of the Baltic Sea, Tellus, 47A, 1013-1031, 1995.

Maiss, M., J. Ilmberger, A. Zenger, and K. O. Münnich, A $\mathrm{SF}_{6}$ tracer study of horizontal mixing in Lake Constance, Aq. Sci., 56(4), Birkhäuser Basel, 1994a.

Maiss, M., J. Ilmberger, and K. O. Münnich, Vertical mixing in Überlingersee (Lake Constance) traced by $\mathrm{A} \mathrm{SF}_{6}$ and heat, Aq. Sci., 56(4), Birkhäuser Basel, 1994b.

Oman, G., Das Verhalten des geschichteten Zürichsees unter äusseren Windlasten, Mitt. Versuchsans. Wasserbau, Hydrol. Glaziol., ETH Zürich, 60, 1982.

Peeters, F., Horizontale Mischung in Seen, Dissertation, ETH Zürich, 1994.

Pohlmann, T., A three dimensional circulation model of the South China Sea, in Eds. J. C. J. Nihoul and B. M. Jamart, Threedimensional models of marine and estuarine dynamics, 245-268, 1987.

Ramming, H.-G., and Z. Kowalik, Numerical modelling of marine hydrodynamics. Elsevier Oceanography Series, 26, Elsevier Amsterdam, 368, 1980.

Rodi, W., Turbulence models and their application in hydraulics $-a$ state of the art review, A. A. Baalkema, Rotterdam, 104, 1993.

Simons, T. J., Circulation models of lakes and inland seas, Can. Bull. Fish. Aq. Sci., 203, Ottawa, 1980.

Song, Y., and D. B. Haidvogel, A semi-implicit ocean circulation model using a generalized topography-following coordinate, J. Comput. Phy., 115, 228-244, 1994.

Svensson, U., A mathematical model of the seasonal thermpcline. University of Lund, Sweden, Rep., 1002, 1978.

Tee, K.-T., Simple models to simulate three-dimensional tidal and residual currents, in Ed. C. N. K. Mooers, Three-dimensional coastal ocean models, Coast. Est. Sci., 4, 125-148, 1987.

Wang, Y., and K. Hutter, A semi-implicit semi-spectral primitive equation model for lake circulation dynamics and its stability performance, J. Comput. Phy., 139, 209-241, 1998.

Wang, Y., and K. Hutter, Methods of substructuring in lake circulation dynamics, Adv. Water Resources, 23, 399-425, 2000.

Wilkin, J. L., J. V. Mansbridge, and K. Hedstrom, An application of the capacitance matrix method to accomodate masked land areas and island circulation in a primitive equation ocean model, Int. J. Num. Methods Fluids, 20, 649-662, 1995.

Zenger, A., J. Ilmberger, G. Heinz, M. Schimmele, and K.-O. Münnich, Untersuchungen zur Struktur der internen Seiches des Bodensees. Wasserwirtschaft, 79(12), 616-624, 1989. 